\title{
Search of reference biomarkers reflecting orbital tissue remodeling in the course of Graves' orbitopathy
}

\author{
Przemyslaw Pawlowski ${ }^{1,2,3}$, Izabela Poplawska ${ }^{1}$, Janusz Mysliwiec ${ }^{4}$, Willem A. Dik ${ }^{5}$, \\ Anja Eckstein ${ }^{6}$, Utta Berchner-Pfannschmidt' ${ }^{6}$, Robert Milewski ${ }^{7}$, Slawomir Lawicki ${ }^{8}$, \\ Zofia Dzieciol-Anikiej ${ }^{9}$, Robert Rejdak ${ }^{10,11}$, Joanna Reszec ${ }^{1}$
}

${ }^{1}$ Department of Medical Pathomorphology, Cathedral of Biostructure, Medical University of Bialystok, Poland ${ }^{2}$ Department of Pediatric Ophthalmology and Strabismus, Medical University of Bialystok, Bialystok, Poland ${ }^{3}$ Department of Ophthalmology, Ludwik Rydygier District Hospital in Suwalki, Poland

${ }^{4}$ Department of Nuclear Medicine, Medical University of Bialystok, Bialystok, Poland

${ }^{5}$ Department of Immunology, Laboratory Medical Immunology, Erasmus MC, University Medical Centre Rotterdam, Rotterdam, The Netherlands

${ }^{6}$ Molecular Ophthalmology, Department of Ophthalmology, University Hospital Essen/University of Duisburg-Essen, Essen, Germany

${ }^{7}$ Department of Statistics and Medical Informatics, Medical University of Bialystok, Bialystok, Poland

${ }^{8}$ Department of Population Medicine and Civilization Diseases Prevention, Medical University of Bialystok, Bialystok, Poland

${ }^{9}$ Department of Rehabilitation, Medical University of Bialystok, Bialystok, Poland

${ }^{10}$ Department of General Ophthalmology, Medical University of Lublin, Lublin, Poland

${ }^{11}$ Department of Experimental Pharmacology, Medical Research Centre,

Polish Academy of Sciences, Warsaw, Poland

\begin{abstract}
Introduction. Graves' orbitopathy (GO) is a complication in Graves' disease (GD) that causes disfigurement and sometimes blindness. The pathogenesis of GO remains unknown, while its symptoms demonstrate dependence between the thyroid gland and the orbit. The ongoing inflammatory process in retrobulbar tissue results in its remodeling characterized by increased volume of the orbital contents involving adipose tissue, with fibrosis and adipogenesis as predominant features. This study was aimed at the immunohistochemical verification of potential contribution and correlation between orbital expressions of IGF-1R, CD34, Foxp-3, PPAR- $\gamma$ and CD4, CD68, TGF- $\beta$, FGF- $\beta$ in severe and mild (long-lasting) GO.

Material and methods. Forty-one orbital tissue specimens - 22 patients with severe GO, 9 patients with mild GO and 10 patients undergoing blepharoplasty as a control group - were processed by routine immunohistochemistry. Results. Increased IGF-1R, CD34 and Foxp-3 expression was found in both severe and mild GO, yet a significant correlation between CD34 and CD4, CD68, TGF- $\beta$, FGF- $\beta$ expressions was observed in long-lasting GO. Conclusions. CD34 expression is proposed to be the marker of orbital tissue remodeling in the course of mild GO. (Folia Histochemica et Cytobiologica 2020, Vol. 58, No. 1, 37-45)
\end{abstract}

Key words: Graves' orbitopathy; CD34; IGF-1R; PPAR- $\gamma$; CD68; TGF- $\beta$; FGF- $\beta$; Foxp-3; tissue remodeling; autoimmunity; IHC 


\section{Introduction}

The pathogenesis of Graves' orbitopathy (GO) remains enigmatic as does the connection between the thyroid and orbit $[1,2]$. GO is characterized by a volume increase of the orbital adipose tissue and orbital remodeling, but the cells and molecules that drive orbital adipogenesis and remodeling remain uncertain. Previously, CD34(+) fibrocytes, monocyte-lineage bone marrow-derived cells, were found to infiltrate the orbit in GO where they could transform into CD34(+) orbital fibroblasts [3, 4]. Moreover, it has been reported that CD34(+) fibrocytes express functional TSH receptor, the central autoantigen in Graves' disease (GD) [5, 6]. In addition to the TSH receptor, orbital fibrocytes (OF) express the insulin-like growth factor 1 receptor (IGF-1R) and the role of TSHR/IGF-1R crosstalk has been recently emphasized in the pathogenesis of GO [7-9]. Previous study had shown that IGF-1R levels were three-fold higher on the orbital fibroblasts (OF) from GO patients compared with control fibroblasts [10]. Most recently, Zhao et al. showed that IGF-1 significantly promoted the cell proliferation and lipid accumulation in stromal cells derived from GO-orbital adipose tissue [11]. Furthermore, Zhao et al. have demonstrated that the protein level of peroxisome proliferator-activated receptor- $\gamma$ (PPAR- $\gamma$ ), involved in insulin action, adipocyte differentiation, lipid metabolism and inflammation, is up-regulated in adipose-derived stromal cells when treated with IGF-1, which involved activation of IGF-1R and subsequent PI3K signaling [11]. These data illustrate that the IGF-1/IGF-1R axis represents a pro-proliferative and pro-adipogenic pathway in orbital tissue from GO [11].

Regulatory $\mathrm{T}$ cells (Tregs) are crucial in suppressing aberrant pathological immune responses, including auto-immune responses [12]. To maintain homeostasis, Tregs use different mechanisms, including the secretion of inhibitory cytokines, but also by cell surface expression of molecules such as cytotoxic T lymphocyte-associate protein 4 (CTLA-4) that is a critical negative regulator of $\mathrm{T}$ cell immunity. Development and functioning of Tregs is controlled by the transcription factor Forkhead box P3 (Foxp-3), while the absence or dysfunction, reduced number of CD4+CD25+Foxp-3+ Tregs associated with auto-immune disease, including GD [13, 14]. Previously, we found enhanced Foxp-3 mRNA expression in GO orbital tissue samples and the positive correlation observed with $\mathrm{CD} 3$ infiltration along with diminished CTLA-4 expression suggesting that inadequate Treg function contributes to the pathogenesis of severe GO [15].
The limitations in our understanding of extrathyroidal Graves' disease immunophenotype result in unsatisfying treatment of severe GO. Therefore, we performed a detailed immunohistochemical study that aimed at comparing the expression pattern of CD34, IGF-1R, Foxp-3, and PPAR- $\gamma$ in the orbital fat/connective tissue of patients with mild/long-lasting and severe/active GO in relation to tissue infiltrating cells and remodeling properties (CD4, CD68, TGF- $\beta$, FGF- $\beta$ ) in these two subgroups of patients with GO.

\section{Material and methods}

Patients and controls. Human orbital tissue samples from twenty seven patients with GO (26 females and 1 male) classified according to the European Group on Graves' Orbitopathy [16], who underwent orbital decompression procedures, were obtained from the orbital tissue bank at the Department of Ophthalmology, University of Essen, Essen, Germany. The mean age of patients at the time of surgery was 44.5 years (range 26-47).

Control, age-matched, fat/connective tissue was obtained from 10 individuals ( 9 females and 1 male) undergoing orbital surgery for blepharoplasty and without history of GO or any orbital inflammatory disease. Surgical specimens were immediately snap-frozen in liquid nitrogen and stored in $-80^{\circ} \mathrm{C}$ until use.

The clinical activity score of GO (CAS) was estimated according to Mourits et al. [17]. The severity of the eye disease was estimated using NOSPECS classification (no signs or symptoms; only signs, on symptoms; signs only; proptosis; eye muscle involvement; corneal involvement; and sight visual acuity reduction) [16].

Patients with severe GO (NOSPECS IV-VI), required orbital bony decompression due to optic nerve compression and limited extraocular muscle functions (22 specimens). Mean duration of thyroid disease was $2.5 \pm 1.5$ years (mean $\pm \mathrm{SD})$ and $1.2 \pm 1$ year for GO. Before the surgery all patients received $>1$ cycle of steroid treatment and orbital irradiation. The mean clinical activity score was $8.5 \pm 2.5$.

Patients with mild GO $(\mathrm{n}=9)$ (NOSPECS III-IV) underwent orbital bony decompression to reduce proptosis. Mean duration of thyroid disease was $3.9 \pm 2$ years and 3.3 \pm 1.9 for GO. Steroid treatment and orbital irradiation characteristics in this group were similar to the patients with severe GO. The mean clinical activity score was $2.2 \pm 0.8$.

The study was approved by the Medical Ethics Committee of the University of Essen, Germany. All procedures performed in studies involving human participants were in accordance with the ethical standards of the institutional and/or national research committee and with the $1964 \mathrm{Hel}-$ sinki declaration and its later amendments or comparable ethical standards. 
Table 1. Antibodies used in the study for immunohistochemical stainings. For negative control phosphate-buffered saline (PBS) was used instead of primary antibody, no staining was detected when the primary antibody was omitted

\begin{tabular}{|l|c|c|c|}
\hline Antibody & Type of antibody & Dilution & Positive control \\
\hline IGF-1R $\alpha$ & $\begin{array}{c}\text { Monoclonal mouse anti-human } \\
\text { Santa Cruz Biotechnology } \\
\text { Antibody (1H7): sc-461 }\end{array}$ & $1: 100$ & Normal kidney vessels tissue \\
\hline Foxp-3 & $\begin{array}{c}\text { Monoclonal rabbit anti-human } \\
\text { Abcam } \\
\text { Antibody (EP373Y): ab81289 }\end{array}$ & $1: 150$ & Human lymph node tissue \\
\hline PPAR- $\gamma$ & $\begin{array}{c}\text { Monoclonal mouse anti-human } \\
\text { Santa Cruz Biotechnology } \\
\text { Antibody (2A11G9): sc-53876 }\end{array}$ & $\begin{array}{c}\text { Monoclonal mouse anti-human } \\
\text { Santa Cruz Biotechnology } \\
\text { Antibody (E-8): sc-7273 }\end{array}$ & $1: 50$ \\
\hline
\end{tabular}

Immunohistochemistry. Formalin-fixed, paraffin-embedded human orbital cryosections ( $4 \mu \mathrm{m}$ thick) were subjected to heat-induced antigen retrieval in EnVision Flex Target Retrieval Solution (DAKO, Glostrup, Denmark) in high $\mathrm{pH}$ (Tris/EDTA buffer, $\mathrm{pH}=9$ ) for the evaluation of CD34 and Foxp-3, and in low $\mathrm{pH}(0.01 \mathrm{M}$ sodium citrate buffer, $\mathrm{pH}=6.0$ ) for IGF-IR and PPAR- $\gamma$ expression. Following the reduction of endogenous peroxidase activity by immersion in $3 \%$ hydrogen peroxidase in methanol for 10 minutes and blockade of nonspecific antigens, slides were incubated with primary antibodies, as indicated in Table 1, overnight at refrigerator temperature $\left(4^{\circ} \mathrm{C}\right)$. Visualization reagent EnVision/HRP (DAKO Omnis) was applied for 20 minutes followed by DAB + Chromogen (DAKO Omnis) solution for 10 minutes. The slides were counterstained with hematoxylin and evaluated under the light microscope. The results of the immunostaining were evaluated in 15 random fields under $20 \times$ magnification per each sample by two independent pathologist blindly. The immunohistochemical assessment of CD4, CD68, TGF- $\beta$ and FGF- $\beta$ was evaluated and described earlier in our previous study [18]. The results were expressed as the percentage of IGF-1R ${ }^{+}, \mathrm{CD} 34^{+}$, PPAR $-\gamma^{+}$orbital fibroblasts (OF) and Foxp $-3^{+}$associated T lymphocytes by the positive staining as follows: $\leq 10 \%$ positive cells - negative $(-)$, between $11 \%$ and $50 \%(+)$, and $\geq 51 \%$ positive cells $(++)$. Although both nuclear and cytoplasmic expressions were observed, it was necessary to use a unified semi-quantitative rating system in order to determine possible dependencies in co-expression.

Statistical analysis. The results were analyzed using Statistica 12.0 for Windows (StatSoft, Poland). Owing to asymmetric data distribution, nonparametric tests were used. Significance levels were calculated in accordance with Kruskal-Wallis test (differences between the control and examined group). The correlations between the examined parameters were assessed with Spearman's rank correlation test. A p-value $<0.05$ was regarded as significant.

\section{Results}

In this study we assessed IGF-1R, CD34, Foxp-3 and PPAR- $\gamma$ expression in the orbital tissue in severe and mild GO compared between each other and with control cases. Obtained results were correlated with CAS of GO patients and with CD4, CD68, TGF- $\beta$ and FGF- $\beta$ expression.

\section{CD34 expression}

CD34 expression was found in OF in orbital connective tissue of GO patients (Fig. 1A-B). $80 \%$ of the evaluated control samples were negative for CD34 expression, while all mild GO cases were evaluated as + while in severe GO cases $\sim 23 \%$ of the orbital tissues were scored as + and $\sim 77 \%$ were rated as ++ (Table 2 and 3 ).

\section{Foxp-3 expression}

Foxp-3 expression (Fig. 1C) was found in associated T lymphocytes from orbital connective tissue of both control and GO patients. From the orbital tissues obtained from the control group, half of them revealed a Foxp-3 staining scored as + while the other half was scored as ++ (Table 2 ). Within the group of mild GO all orbital tissues were evaluated as + while in the severe GO group $\sim 59 \%$ of the orbital tissues were scored as,$++ \sim 32 \%$ as + and $\sim 9 \%$ as negative (Table 2 and Table 3 ).

\section{IGF-1R expression}

IGF-1R was undetectable in the orbital tissue from all control cases (Table 2). However, IGF-1R expression 



Figure 1A-B. The expression of CD34 in fibroblasts of orbit connective tissue in mild Graves' orbitopathy (GO) (A) and severe GO (B). The immunohistochemical (IHC) staining was performed as described in Methods. Arrowheads indicate immunoreactivity.

Table 2. The descriptive statistics of evaluated score for immunohistochemical staining of the respective antigens in control and Graves' orbitopathy (GO) patients with mild and severe disease activity. The p-value presented in the Kruskal-Wallis test column is a comparison of the given sub-group with the control group

\begin{tabular}{|l|c|c|c|c|c|c|c|c|c|}
\hline Antigen and disease activity & $\mathbf{n}$ & Mean & SD & $\begin{array}{c}\text { Medi- } \\
\text { an }\end{array}$ & Min & Max & Q1 & Q3 & p (Kruskal-Wallis) \\
\hline IGF-1R, severe GO & 22 & 1.9 & 0.4 & 2.0 & 1.0 & 2.0 & 2.0 & 20. & $\mathrm{p}=0.0000$ \\
\hline IGF-1R mild GO & 9 & 0.9 & 0.6 & 1.0 & 0.0 & 2.0 & 1.0 & 1.0 & $\mathrm{p}=0.0000$ \\
\hline IGF-1R control & 10 & 0.0 & 0.0 & 0.0 & 0.0 & 0.0 & 0.0 & 0.0 & $\mathrm{p}=0.0000$ \\
\hline CD34 severe GO & 22 & 1.8 & 0.4 & 2.0 & 1.0 & 2.0 & 2.0 & 2.0 & $\mathrm{p}=0.0000$ \\
\hline CD34 mild GO & 9 & 1.0 & 0.0 & 1.0 & 1.0 & 1.0 & 1.0 & 1.0 & $\mathrm{p}=0.0351$ \\
\hline CD34 contr. & 10 & 0.2 & 0.4 & 0.0 & 0.0 & 1.0 & 0.0 & 0.0 & $\mathrm{p}=0.0351$ \\
\hline Foxp-3 severe GO & 22 & 1.5 & 0.7 & 2.0 & 0.0 & 2.0 & 1.0 & 2.0 & $\mathrm{p}=0.3213$ \\
\hline Foxp-3 mild GO & 9 & 1.0 & 0.0 & 1.0 & 1.0 & 1.0 & 1.0 & 1.0 & $\mathrm{p}=0.3213$ \\
\hline Foxp-3 contr. & 10 & 1.5 & 0.5 & 1.5 & 1.0 & 2.0 & 1.0 & 2.0 & \\
\hline PPAR- $\gamma$ severe GO & 22 & 1.4 & 0.5 & 1.0 & 1.0 & 2.0 & 1.0 & 2.0 & 1.0 \\
\hline PPAR- $\gamma$ mild GO & 9 & 1.2 & 0.4 & 1.0 & 1.0 & 2.0 & 1.0 & 1.0 & \\
\hline PPAR- $\gamma$ contr. & 10 & 1.5 & 0.7 & 2.0 & 0.0 & 2.0 & 1.0 & 2.0 & \\
\hline
\end{tabular}

was found in $\mathrm{OF}$ in connective tissue and surrounding the blood vessels in GO specimen (Fig. 1D-E). 77\% of mild GO cases were evaluated as + while in case of patients with severe $\mathrm{GO} \sim 77 \%$ of the orbital tissue were scored as ++ (Table 2 and Table 3 ).

\section{PPAR- $\gamma$ expression}

PPAR- $\gamma$ expression was also found in OF in orbital connective tissue of control and $\mathrm{GO}$ patients (Fig. $1 \mathrm{~F}-\mathrm{G}$ ). $60 \%$ of the orbital tissues from the control group showed a positive staining estimated as ++ , while $30 \%$ were scored as + and $10 \%$ as negative (Table 2 ).
Within the mild GO subgroup $\sim 78 \%$ of the orbital tissues were scored as + and $\sim 22 \%$ as ++ (Table 2 ). Orbital tissues from the severe GO group were scored as + in $\sim 64 \%$ of the cases and the remaining $36 \%$ were scored as ++ (Table 2 and Table 3$)$.

\section{Correlation of IGF-1R and CD34 with CAS}

Using the Spearman's rank correlation we found that IGF-1R expression was positively and strongly correlated with CAS $(\mathrm{R}=0.6521, \mathrm{p}=0.00007)$ in the whole group of GO patients. CD34 expression also correlated positively with CAS in the total $\mathrm{GO}(\mathrm{p}=0.03)$. However, 
Table 3. Number of patients and the percentage of IGF-1R, CD34, Foxp-3 and PPAR- $\gamma$ expression within scores $0(-), 1$ $(+)$, and $2(++)$ in the examined groups of control subjects and Graves' orbitopathy patients

\begin{tabular}{|l|c|c|c|c|}
\hline IGF-1R expression & Control & Mild GO & Severe GO & Sum \\
\hline 0 & $\mathbf{1 0}(100 \%)$ & $\mathbf{1}(11.1 \%)$ & $\mathbf{0}$ & 11 \\
\hline 1 & $\mathbf{0}$ & $\mathbf{7}(77.8 \%)$ & $\mathbf{5}(22.7 \%)$ & 12 \\
\hline 2 & $\mathbf{0}$ & $\mathbf{1}(11.1 \%)$ & $\mathbf{1 7}(77.3 \%)$ & 18 \\
\hline CD34 expression & Control & Mild GO & Severe GO & Sum \\
\hline 0 & $\mathbf{8}(80.0 \%)$ & $\mathbf{0}$ & $\mathbf{0}$ & 8 \\
\hline 1 & $\mathbf{2}(20.0 \%)$ & $\mathbf{9}(100 \%)$ & $\mathbf{5}(22.7 \%)$ & 16 \\
\hline 2 & $\mathbf{0}$ & $\mathbf{0}$ & $\mathbf{1 7}(77.3 \%)$ & 17 \\
\hline Foxp-3 expression & Control & Mild GO & Severe GO & Sum \\
\hline 0 & $\mathbf{0}$ & $\mathbf{0}$ & $\mathbf{2}(9.1 \%)$ & 2 \\
\hline 1 & $\mathbf{5}(50 \%)$ & $\mathbf{9}(100 \%)$ & $\mathbf{7}(31.8 \%)$ & 21 \\
\hline 2 & $\mathbf{5}(50 \%)$ & $\mathbf{0}$ & $\mathbf{1 3}(59.1 \%)$ & 18 \\
\hline PPAR- $\gamma$ expression & Control & Mild GO & Severe GO & Sum \\
\hline 0 & $\mathbf{1}(10 \%)$ & $\mathbf{0}$ & $\mathbf{0}$ & 1 \\
\hline 1 & $\mathbf{3}(30 \%)$ & $\mathbf{7}(77.8 \%)$ & $\mathbf{1 4}(63.7 \%)$ & 24 \\
\hline 2 & $\mathbf{6}(60 \%)$ & $\mathbf{2}(22.2 \%)$ & $\mathbf{8}(36.4 \%)$ & 16 \\
\hline
\end{tabular}

Immunohistochemistry score: 0 - less than $10 \%$ positive in 15 representative high power fields (HPF); $1-10 \%-50 \%$ positive cells in $15 \mathrm{HPF}$; 2 - more than $50 \%$ positive cells in $15 \mathrm{HPF}$.

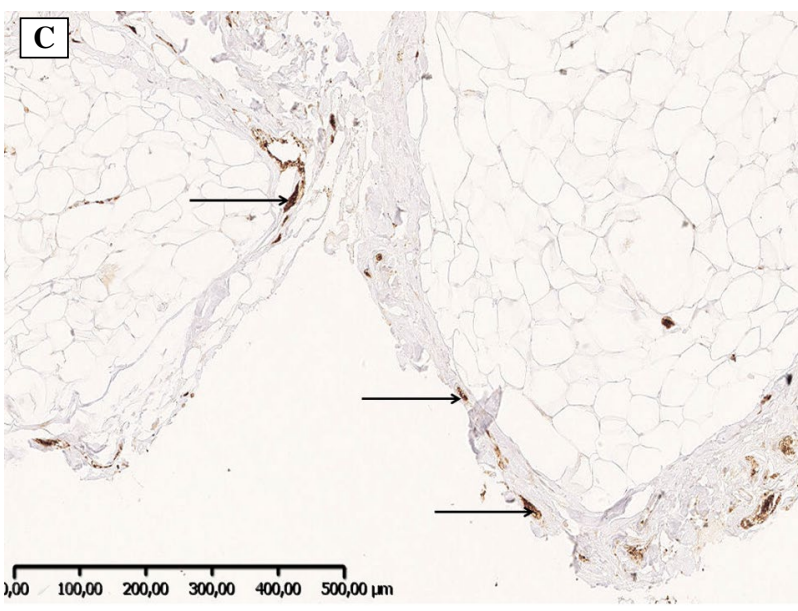

Figure 1C. The expression of FoxP3 on lymphocytes surrounding blood vessels within orbital connective tissue in Graves' orbitopathy (arrows). The IHC staining was performed as described in Methods.

neither Foxp-3 nor PPAR- $\gamma$ expression showed any correlation with CAS of GO patients (Table 4).

\section{Correlation with CD4, CD68, FGF- $\beta$ and TGF- $\beta$}

In addition, using the Spearman's rank correlation we examined the relationship between the expression of

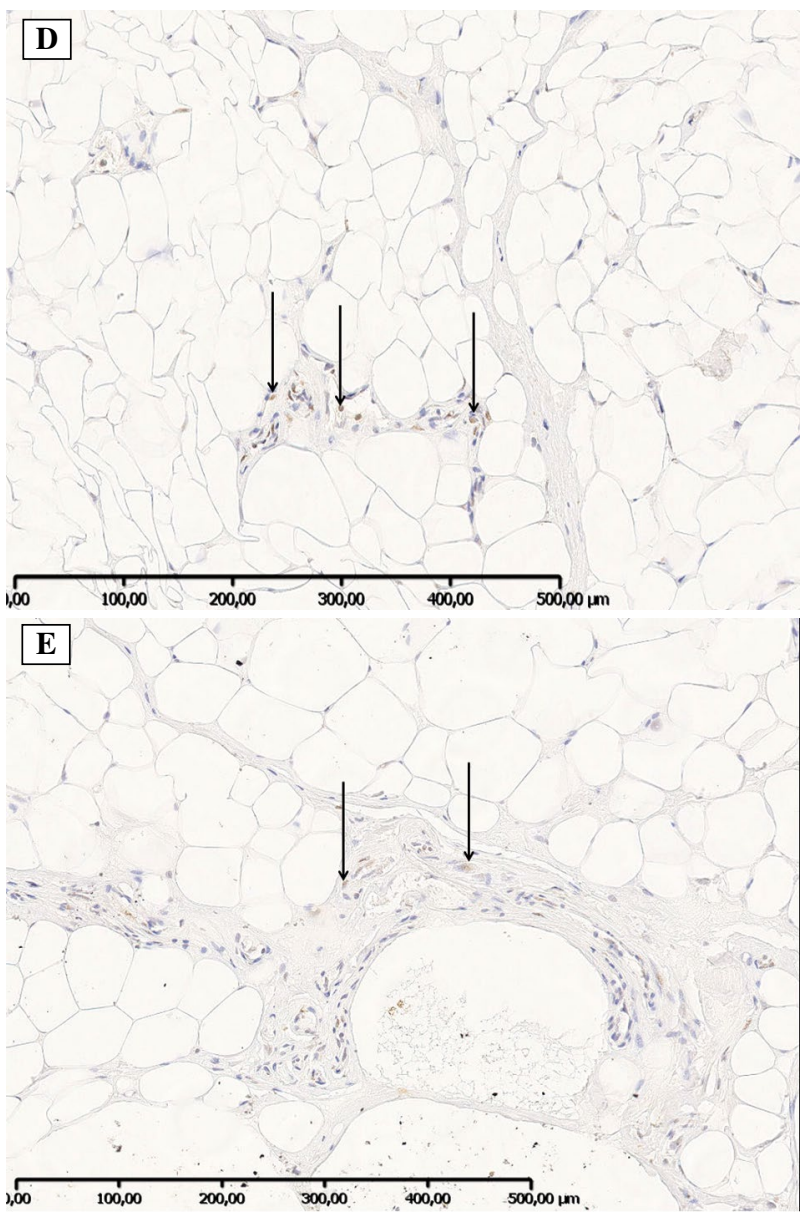

Figure 1D-E. IGF-IR immunoreactivity (arrows) in fibroblasts of orbital connective tissue obtained from patients with mild GO (D) and severe GO (E). The IHC staining was performed as described in Methods.

IGF-1R or CD34 with immunohistochemical staining analysis for CD4, CD68, FGF- $\beta$ and TGF- $\beta$ which had been conducted on the same orbital tissues in one of our previous studies [13]. A positive correlation was found between IGF-1R or CD34 and all parameters, when GO cases were considered without further subdivision into mild and severe subgroups (Table 5). In mild GO a statistical significant correlation was observed between the expression of CD34 and CD4, CD68, TGF- $\beta$ or FGF- $\beta$. Further, a clear trend towards a positive correlation was observed between the expression of CD34 and TGF- $\beta$ in severe GO $(p=0.07613)$. IGF-1R expression only revealed positive and significant correlations with FGF- $\beta$ in mild GO and with CD4 in severe GO (Table 5).

\section{Discussion}

In GO the ongoing inflammatory process in the retrobulbar tissue results in adipogenesis, volume increase 


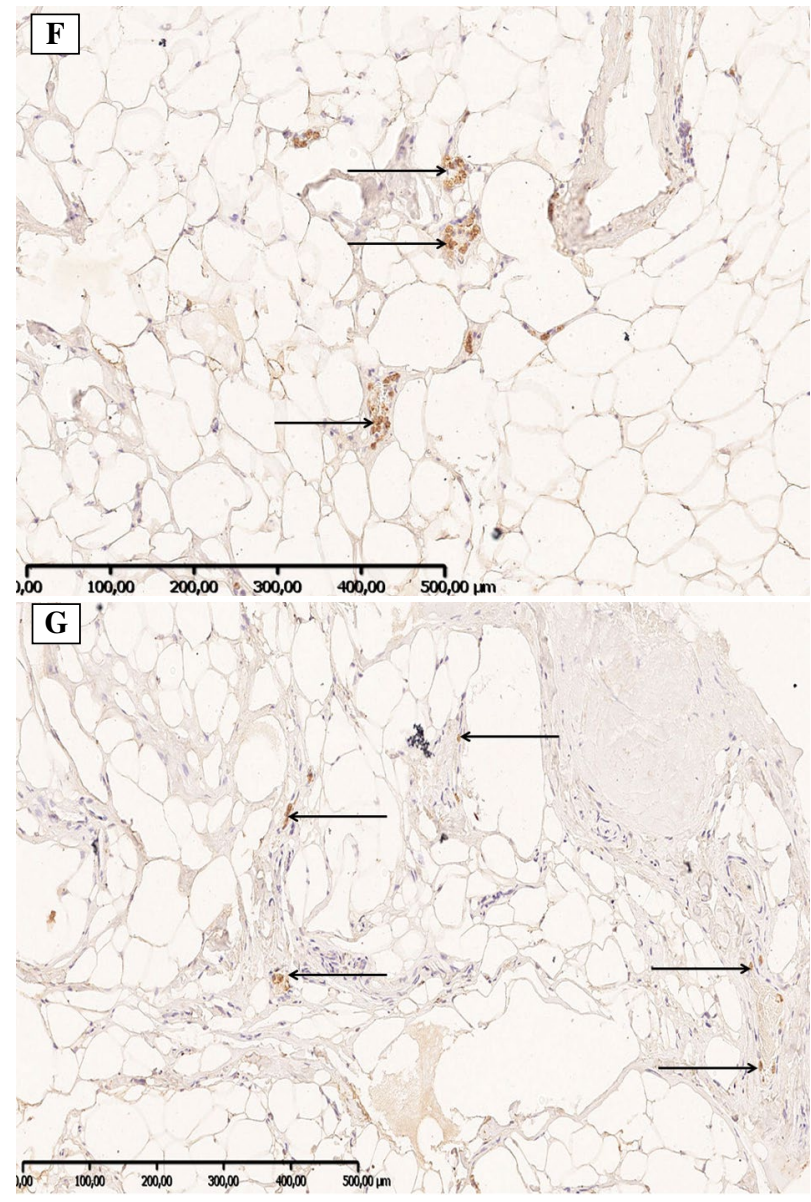

Figure 1F-G. PPAR- $\gamma$ immunoreactivity expression in fibroblasts of orbital connective tissue in mild GO (F) and severe GO (G). The IHC staining was performed as described in Methods.

Table 4. Spearman's correlation of clinical activity score (CAS) values with examined parameters in patients with Grave's orbitopathy

\begin{tabular}{|l|c|c|}
\hline \multirow{2}{*}{} & \multicolumn{2}{|c|}{ CAS } \\
\cline { 2 - 3 } & R value & P value \\
\hline IGF-1R expression & 0.6521 & 0.00007 \\
\hline CD34 expression & 0.3872 & 0.03127 \\
\hline Foxp-3 expression & 0.2948 & 0.10738 \\
\hline PPAR- $\gamma$ expression & 0.1384 & 0.45664 \\
\hline
\end{tabular}

of the orbital adipose-connective tissue and, in the end, remodeling characterized by fibrosis. These processes encompass both changes in cellular composition and extracellular matrix within the orbital tissue, which are controlled by stimulatory factors such as growth factors and cytokines released by infiltrating immune cells $[2,18,19]$.
Table 5. Spearman's rank correlations of CD4, CD68, FGF- $\beta$ and TGF- $\beta$ with IGF-1R or CD34 expression without dividing into groups and within mild and severe Grave's orbitopathy (GO)

\begin{tabular}{|c|c|c|c|c|}
\hline & \multicolumn{4}{|c|}{$\begin{array}{l}\text { Without dividing into groups } \\
\qquad(\mathbf{n}=\mathbf{3 1})\end{array}$} \\
\hline & \multicolumn{2}{|c|}{$R$ value } & \multicolumn{2}{|c|}{$P$ value } \\
\hline & \multicolumn{4}{|c|}{ CD4 expression } \\
\hline IGF-1R expression & \multicolumn{2}{|c|}{0.6277} & \multicolumn{2}{|c|}{0.00001} \\
\hline \multirow{2}{*}{ CD34 expression } & & 334 & 0.0 & 033 \\
\hline & \multicolumn{4}{|c|}{ CD68 expression } \\
\hline IGF-1R expression & \multicolumn{2}{|c|}{0.5445} & \multicolumn{2}{|c|}{0.00016} \\
\hline \multirow[t]{2}{*}{ CD34 expression } & & 442 & 0.0 & 361 \\
\hline & \multicolumn{4}{|c|}{ FGF- $\beta$ expression } \\
\hline IGF-1R expression & \multicolumn{2}{|c|}{0.6455} & \multicolumn{2}{|c|}{0.00000} \\
\hline \multirow[t]{2}{*}{ CD34 expression } & \multicolumn{2}{|c|}{0.5330} & \multicolumn{2}{|c|}{0.00033} \\
\hline & \multicolumn{4}{|c|}{ TGF $-\beta$ expression } \\
\hline IGF-1R expression & \multicolumn{2}{|c|}{0.7989} & \multicolumn{2}{|c|}{0.00000} \\
\hline \multirow[t]{4}{*}{ CD34 expression } & \multicolumn{2}{|c|}{0.6369} & \multicolumn{2}{|c|}{0.00001} \\
\hline & \multicolumn{2}{|c|}{ Mild GO (n = 9) } & \multicolumn{2}{|c|}{ Severe GO $(\mathrm{n}=22)$} \\
\hline & $R$ value & $P$ value & $R$ value & $P$ value \\
\hline & \multicolumn{4}{|c|}{ CD4 expression } \\
\hline IGF-1R expression & 0.6754 & 0.2237 & 0.5587 & 0.00846 \\
\hline \multirow[t]{2}{*}{ CD34 expression } & 0.5334 & 0.00033 & 0.0925 & 0.1476 \\
\hline & \multicolumn{4}{|c|}{ CD68 expression } \\
\hline IGF-1R expression & 0.3487 & 0.1876 & 0.0654 & 0.3256 \\
\hline \multirow[t]{2}{*}{ CD34 expression } & 0.4442 & 0.00361 & 0.2421 & 0.5421 \\
\hline & \multicolumn{4}{|c|}{ FGF- $\beta$ expression } \\
\hline IGF-1R expression & -0.7043 & 0.02298 & 0.6054 & 0.2877 \\
\hline \multirow[t]{2}{*}{ CD34 expression } & 0.5330 & 0.02298 & 0.4334 & 0.1233 \\
\hline & \multicolumn{4}{|c|}{ TGF $-\beta$ expression } \\
\hline IGF-1R expression & 0.7155 & 0.0928 & 0.1054 & 0.2227 \\
\hline CD34 expression & 0.6369 & 0.00001 & -0.3953 & 0.07613 \\
\hline
\end{tabular}

Tsui et al. suggested that cross-talk between the TSH and IGF-1 receptors plays a role in GO pathogenesis [10], which has been further supported by findings of numerous other scientific groups $[7,9$, 20]. Interestingly, IGF-1 promotes cell proliferation and lipid accumulation within orbital adipose tissue-derived stromal cells from patients with GO [11]. Recently we revealed that IGF-1 stimulation of peripheral blood mononuclear cells (PBMC) derived from GO patients resulted in significant increase of Treg frequency, thus demonstrating Treg-enhancing effects of IGF-1 [21]. This effect of IGF-1 may also impact Treg numbers locally within the orbital tissue 
from $\mathrm{GO}$ and therefore we compared the expression pattern of the IGF-1R with that of Foxp-3 in this current study. We demonstrated the medium Foxp-3 expression (11\% to $50 \%$ positive cells) in all orbital tissues from patients with mild GO, whereas in severe GO majority of patients $(\sim 59 \%$ of cases revealed a staining pattern of $\geq 50 \%$ positive cells). It could suggest that orbital accumulation of Foxp-3 could suppress $\mathrm{CD} 4+$ mediated inflammatory process in mild GO more than in severe GO and it might be not sufficient in overcoming severe GO.

In accordance, Kahaly et al. observed that peripheral blood T-cells from GO patients more strongly upregulated Foxp-3 and CD25 upon stimulation with rabbit anti-T-lymphocyte globulin (rATG) than T-cells from patients with Graves' disease without orbital involvement as well as healthy controls [22]. In addition, recently Bilbao et al. found that human IGF-1 stimulates proliferation of Tregs [23]. Thus, Tregs as immunosuppressive cells, generally suppress or downregulate induction and proliferation of effector $\mathrm{T}$ cells, maintaining tolerance to self-antigens and preventing autoimmune reactions [24]. Therefore, within GO orbital tissue Tregs might be upregulated by IGF-1R stimulation.

Recent research has found that the cytokine TGF- $\beta$ is essential for Tregs to differentiate from naïve CD4+ cells and is important in maintaining Treg homeostasis [25]. The overexpression of this protein induces the differentiation and expansion of Tregs [11]. The relationship between the disease duration, as in patients with mild GO, and TGF- $\beta$ secretion was demonstrated in our previous studies [18]. Moreover, previously we found enhanced Foxp-3 mRNA expression in GO orbital tissue which correlated with CD3 expression and serum CRP levels suggesting its involvement in the pathogenesis of severe GO [15]. In accordance, Chen et al. showed that IGF-1R inhibition diminished trafficking of CD4+ T cells as well as IGF-1 actions in fibroblasts [26]. Moreover, Frostad et al. found that IGF-1 has a costimulatory effect on proliferation of progenitors derived from human umbilical cord CD34+ cells [27]. In the context of these studies we have demonstrated the significant correlation between IGF-1R and CD4 expression in patients with severe GO confirming the assumption about the positive relationship between them.

Previous papers suggested, that IGF-1R signaling may accelerate severity of GO which may be related to its enhanced expression by orbital fibroblasts and T-lymphocytes from GO patients. The production of $\mathrm{T}$-cell chemoattractants, hyaluronan and adipogenesis by orbital fibroblasts/stromal cells upon IGF-1R activation and the role of circulating stimulatory IGF-1R autoantibodies (IGF1R-Abs), however controversial
[28]), were also detected [11, 29, 30]. Notwithstanding, Bilbao et al. demonstrated that IGF-1 directly targets human and mouse Tregs thereby stimulating their proliferation. In addition, they demonstrated that systemically delivered IGF-1 suppressed autoimmune symptoms in mouse models of multiple sclerosis and type-1 diabetes, which involved local Treg recruitment and modulation of Treg transcriptome [23]. Moreover, Zhao et al. claimed that the IGF-1/IGF-1R axis represents a pro-proliferative and pro-adipogenic pathway in orbital tissue from GO [11]. Indeed, our results indicate that elevated IGF-1R expression may exert an important role in the pathogenesis of severe GO, as orbital tissue from most severe GO patients ( $\sim 77 \%$ of cases) revealed robust staining for IGF1R ( $\geq 50 \%$ positive cells) whereas in mild GO the expression of IGF-1R was far less pronounced (78\% revealed a staining pattern of between $11 \%$ and $50 \%$ positive cells). Moreover the negative correlation between IGF-1R and FGF- $1 \beta$ in mild GO could suggest that the pro-proliferative and pro-fibroblastic (proadipogenic) properties of IGF-1R stimulation may be milder or altered in this GO group. Yet, to elucidate the exact contribution of orbital IGF-1R expression in $\mathrm{GO}$ further studies are required.

The signaling pathways of adipogenesis have been shown to involve both TSH-R and IGF-1R and it appears both TSH-R and IGF-1R share the same intracellular AKT/PI3K signaling to affect adipogenesis probably by co-localization of these two receptors on orbital fibroblasts [8]. In addition, PPAR- $\gamma$ involved in adipocyte differentiation, lipid metabolism and inflammation is a potent stimulator for adipogenesis in GO as well. Recently, Alevizaki et al. observed that the distribution of the Pro(12)Ala PPAR- $\gamma$ gene polymorphism is equally present in patients with GD with or without GO [31]. However, among patients with GO this polymorphism is associated with less-severe and less-active disease. Alevizaki et al. concluded that the PPAR- $\gamma$ gene does not seem to be involved in the predisposition for GO. Interestingly, Zhao et al. demonstrated that activation of IGF-1R and PI3K signaling pathways resulted in PPAR- $\gamma$ up-regulation in adipose tissue-derived stromal cells [11]. Yet, in our experiments we did not find any significant relation between PPAR- $\gamma$ and the other molecules studied. However, the steroid treatment our patients received may have hampered PPAR- $\gamma$ expression in both groups of GO analyzed. Nevertheless, comparison of PPAR- $\gamma$ staining in patients with mild GO versus severe GO revealed that more mild long lasting cases had a score 1 ( $~ 78 \%$ of cases) than severe active cases ( $\sim 63 \%$ of cases), suggestive of its role in a long term tissue remodeling and less-active disease. 
Recently, CD34 + fibrocytes were found to express functional TSH receptor, the central antigen in GD $[4,6,32]$. Kozdon et al. observed that CD34 protein was expressed by $45 \%$ up to $70 \%$ of the GO orbital fibroblasts [33]. Furthermore, CD4+ T cells secrete cytokines that stimulate the production of mucopolysaccharides by orbital fibroblasts, which contributes to edema in the extraocular muscles [33]. In orbital tissue from mild GO we found a positive correlation between CD34 expressing cells and CD4+ T-cell and macrophage $(\mathrm{CD} 68+)$ infiltration. Furthermore, the positive relationship of CD34+ cells with TGF- $\beta$ and FGF- $\beta$ expression in longer-lasting GO, suggest that $\mathrm{T}$ cells and macrophages may mediate an immune response stimulating orbital fibroblasts, consequently CD34+ cells may thus exhibit a key role in orbital tissue remodeling in these patients [18]. Despite the increased expression of IGF-1R, CD34 and Foxp-3 in both mild and severe GO we observed a positive correlation between IGF-1R, CD34 and CAS coefficient, which may indicate that these molecules are expressed at higher level in patients with acute disease.

In conclusion, our observations support involvement of the IGF-1 receptor, Foxp-3 expressing Tregs, and CD34+ expressing cells (fibroblasts/fibrocytes) in the development of both mild and severe GO. Fibrosis in mild GO is associated with TGF- $\beta$ and FGF- $\beta$ expression, which is mediated by helper T cells and macrophages and correlates with CD34 expression. Thus, due to the multidirectional relationship with other molecules and factors, CD34 expression rather than IGF-1R or Foxp-3 is proposed to represent a marker of orbital tissue remodeling in the course of GO.

\section{Declaration of interest}

The authors report no conflicts of interest. The authors alone are responsible for the content and writing of the article.

\section{Funding}

This research was supported by a grant of Medical University of Bialystok grant no. N/ST/ZB/16/003/1194.

\section{References}

1. Wang Y, Smith TJ. Current concepts in the molecular pathogenesis of thyroid-associated ophthalmopathy. Invest Ophthalmol Vis Sci. 2014; 55(3): 1735-1748, doi: 10.1167/iovs.1414002, indexed in Pubmed: 24651704.

2. Smith T, Hegedüs L. Graves' Disease. New England Journal of Medicine. 2016; 375(16): 1552-1565, doi: 10.1056/nejmra1510030.

3. Douglas RS, Afifiyan NF, Hwang CJ, et al. Increased generation of fibrocytes in thyroid-associated ophthalmopathy. J Clin Endocrinol Metab. 2010; 95(1): 430-438, doi: 10.1210/ jc.2009-1614, indexed in Pubmed: 19897675.
4. Smith TJ, Padovani-Claudio DA, Lu Y, et al. Fibroblasts expressing the thyrotropin receptor overarch thyroid and orbit in Graves' disease. J Clin Endocrinol Metab. 2011; 96(12): 3827-3837, doi: 10.1210/jc.2011-1249, indexed in Pubmed: 21956421.

5. Li He, Fitchett $\mathrm{C}$, Kozdon K, et al. Independent adipogenic and contractile properties of fibroblasts in Graves' orbitopathy: an in vitro model for the evaluation of treatments. PLoS One. 2014; 9(4): e95586, doi: 10.1371/journal.pone.0095586, indexed in Pubmed: 24751986.

6. Gillespie EF, Papageorgiou KI, Fernando R, et al. Increased expression of TSH receptor by fibrocytes in thyroid-associated ophthalmopathy leads to chemokine production. J Clin Endocrinol Metab. 2012; 97(5): E740-E746, doi: 10.1210/ jc.2011-2514, indexed in Pubmed: 22399514.

7. Krieger CC, Place RF, Bevilacqua C, et al. TSH/IGF-1 receptor cross talk in graves' ophthalmopathy pathogenesis. J Clin Endocrinol Metab. 2016; 101(6): 2340-2347, doi: 10.1210/jc.2016-1315, indexed in Pubmed: 27043163.

8. Khong JJ, McNab AA, Ebeling PR, et al. Pathogenesis of thyroid eye disease: review and update on molecular mechanisms. Br J Ophthalmol. 2016; 100(1): 142-150, doi: 10.1136/ bjophthalmol-2015-307399, indexed in Pubmed: 26567024.

9. Wiersinga WM. Autoimmunity in Graves' ophthalmopathy: the result of an unfortunate marriage between TSH receptors and IGF-1 receptors? J Clin Endocrinol Metab. 2011; 96(8): 2386-2394, doi: 10.1210/jc.2011-0307, indexed in Pubmed: 21677036 .

10. Tsui S, Naik V, Hoa N, et al. Evidence for an association between thyroid-stimulating hormone and insulin-like growth factor 1 receptors: a tale of two antigens implicated in Graves' disease. J Immunol. 2008; 181(6): 4397-4405, doi: 10.4049/ jimmunol.181.6.4397, indexed in Pubmed: 18768899.

11. Zhao P, Deng Y, Gu P, et al. Insulin-like growth factor 1 promotes the proliferation and adipogenesis of orbital adipose-derived stromal cells in thyroid-associated ophthalmopathy. Exp Eye Res. 2013; 107: 65-73, doi: 10.1016/j. exer.2012.11.014, indexed in Pubmed: 23219871.

12. Sakaguchi S. Regulatory T cells: history and perspective. Methods Mol Biol. 2011; 707: 3-17, doi: 10.1007/978-1-61737979-6_1, indexed in Pubmed: 21287325.

13. Klatka M, Grywalska E, Partyka M, et al. Th17 and Treg cells in adolescents with Graves' disease. Impact of treatment with methimazole on these cell subsets. Autoimmunity. 2014; 47(3): 201-211, doi: 10.3109/08916934.2013.879862, indexed in Pubmed: 24443787.

14. Ban $\mathrm{Y}$, Tozaki $\mathrm{T}$, Tobe $\mathrm{T}$, et al. The regulatory $\mathrm{T}$ cell gene FOXP3 and genetic susceptibility to thyroid autoimmunity: an association analysis in Caucasian and Japanese cohorts. J Autoimmun. 2007; 28(4): 201-207, doi: 10.1016/j. jaut.2007.02.016, indexed in Pubmed: 17418529.

15. Pawlowski P, Wawrusiewicz-Kurylonek N, Eckstein A, et al. Disturbances of modulating molecules (FOXP3, CTLA$4 / \mathrm{CD} 28 / \mathrm{B} 7$, and CD40/CD40L) mRNA expressions in the orbital tissue from patients with severe graves' ophthalmopathy. Mediators Inflamm. 2015; 2015: 340934, doi: 10.1155/2015/340934, indexed in Pubmed: 25653477.

16. Bartalena L, Baldeschi L, Boboridis K, et al. European Group on Graves' Orbitopathy (EUGOGO). The 2016 European Thyroid Association/European Group on Graves' Orbitopathy Guidelines for the Management of Graves' Orbitopathy. Eur Thyroid J. 2016; 5(1): 9-26, doi: 10.1159/000443828, indexed in Pubmed: 27099835.

17. Mourits MP, Prummel MF, Wiersinga WM, et al. Clinical activity score as a guide in the management of patients with 
Graves' ophthalmopathy. Clin Endocrinol (Oxf). 1997; 47(1): 9-14, doi: 10.1046/j.1365-2265.1997.2331047.x, indexed in Pubmed: 9302365.

18. Pawlowski P, Reszec J, Eckstein A, et al. Markers of inflammation and fibrosis in the orbital fat/connective tissue of patients with Graves' orbitopathy: clinical implications. Mediators Inflamm. 2014; 2014: 412158, doi: 10.1155/2014/412158, indexed in Pubmed: 25309050.

19. Dik WA, Virakul S, van Steensel L. Current perspectives on the role of orbital fibroblasts in the pathogenesis of Graves' ophthalmopathy. Exp Eye Res. 2016; 142: 83-91, doi 10.1016/j.exer.2015.02.007, indexed in Pubmed: 26675405.

20. Smith TJ, Hegedüs L, Douglas RS. Role of insulin-like growth factor-1 (IGF-1) pathway in the pathogenesis of Graves' orbitopathy. Best Pract Res Clin Endocrinol Metab. 2012; 26(3): 291-302, doi: 10.1016/j.beem.2011.10.002, indexed in Pubmed: 22632366.

21. Pawlowski P, Grubczak K, Kostecki J, et al. Decreased Frequencies of Peripheral Blood CD4+CD25 + CD127-Foxp3+ in Patients with Graves' Disease and Graves' Orbitopathy: Enhancing Effect of Insulin Growth Factor-1 on Treg Cells. Horm Metab Res. 2017; 49(3): 185-191, doi: 10.1055/s-0042122780, indexed in Pubmed: 28222462.

22. Kahaly GJ, Shimony O, Gellman YN, et al. Regulatory T-cells in Graves' orbitopathy: baseline findings and immunomodulation by anti-T lymphocyte globulin. J Clin Endocrinol Metab. 2011; 96(2): 422-429, doi: 10.1210/jc.2010-1424, indexed in Pubmed: 21147887.

23. Bilbao D, Luciani L, Johannesson B, et al. Insulin-like growth factor-1 stimulates regulatory $\mathrm{T}$ cells and suppresses autoimmune disease. EMBO Mol Med. 2014; 6(11): 1423-1435, doi: 10.15252/emmm.201303376, indexed in Pubmed: 25339185.

24. Bettelli E, Carrier Y, Gao W, et al. Reciprocal developmental pathways for the generation of pathogenic effector TH17 and regulatory T cells. Nature. 2006; 441(7090): 235-238, doi: 10.1038/nature04753, indexed in Pubmed: 16648838.

25. Schmidt, A., Éliás, S., Joshi, R. N., \& Tegnér, J. . In vitro differentiation of human CD4+ FOXP3+ induced regulatory T cells (iTregs) from naïve CD4+ T cells using a TGF- $\beta$-containing protocol. J Visual Exp. 2016; 118: e55015.
26. Chen H, Mester T, Raychaudhuri N, et al. Teprotumumab, an IGF-1R blocking monoclonal antibody inhibits TSH and IGF-1 action in fibrocytes. J Clin Endocrinol Metab. 2014; 99(9): E1635-E1640, doi: 10.1210/jc.2014-1580, indexed in Pubmed: 24878056.

27. Frostad S, Bjerknes R, Abrahamsen JF, et al. Insulin-like growth factor-1 (IGF-1) has a costimulatory effect on proliferation of committed progenitors derived from human umbilical cord CD34+ cells. Stem Cells. 1998; 16(5): 334-342, doi: 10.1002/stem.160334, indexed in Pubmed: 9766813.

28. Minich WB, Dehina N, Welsink T, et al. Autoantibodies to the IGF1 receptor in Graves' orbitopathy. J Clin Endocrinol Metab. 2013; 98(2): 752-760, doi: 10.1210/jc.2012-1771, indexed in Pubmed: 23264397.

29. Douglas RS, Gianoukakis AG, Kamat S, et al. Aberrant expression of the insulin-like growth factor-1 receptor by $\mathrm{T}$ cells from patients with Graves' disease may carry functional consequences for disease pathogenesis. J Immunol. 2007; 178(5): 3281-3287, doi: 10.4049/jimmunol.178.5.3281, indexed in Pubmed: 17312178.

30. Varewijck AJ, Boelen A, Lamberts SWJ, et al. Circulating IgGs may modulate IGF-I receptor stimulating activity in a subset of patients with Graves' ophthalmopathy. J Clin Endocrinol Metab. 2013; 98(2): 769-776, doi: 10.1210/jc.20122270, indexed in Pubmed: 23295466.

31. Alevizaki M, Mantzou E, Cimponeriu A, et al. The Pro 12 Ala PPAR gamma gene polymorphism: possible modifier of the activity and severity of thyroid-associated orbitopathy (TAO). Clin Endocrinol (Oxf). 2009; 70(3): 464-468, doi: 10.1111/j.1365-2265.2008.03343.x, indexed in Pubmed: 18624999.

32. Smith TJ. TSH-receptor-expressing fibrocytes and thyroid-associated ophthalmopathy. Nat Rev Endocrinol. 2015; 11(3): 171-181, doi: 10.1038/nrendo.2014.226, indexed in Pubmed: 25560705 .

33. Kozdon K, Fitchett C, Rose GE, et al. Mesenchymal stem cell-like properties of orbital fibroblasts in graves' orbitopathy. Invest Ophthalmol Vis Sci. 2015; 56(10): 5743-5750, doi: 10.1167/iovs.15-16580, indexed in Pubmed: 26325413.

Submitted: 24 October, 2018

Accepted after reviews: 26 February, 2020 Available as AoP: 16 March, 2020 